\title{
Genetic Dissociation of Opiate Tolerance and Physical Dependence in $\delta$-Opioid Receptor-1 and Preproenkephalin Knock-Out Mice
}

\author{
Joshua F. Nitsche, ${ }^{1}$ Alwin G. P. Schuller, ${ }^{1}$ Michael A. King, ${ }^{2}$ Min Zengh, ${ }^{1}$ Gavril W. Pasternak, ${ }^{2}$ and \\ John E. Pintar ${ }^{1}$ \\ ${ }^{1}$ Department of Neuroscience and Cell Biology, University of Medicine and Dentistry of New Jersey-Robert Wood \\ Johnson Medical School, Piscataway, New Jersey 08854, and 'Laboratory of Neuropharmacology, Memorial \\ Sloan-Kettering Cancer Center, New York, New York 10021
}

Previous experiments have shown that mice lacking a functional $\delta$-opioid receptor $(D O R-1)$ gene do not develop analgesic tolerance to morphine. Here we report that mice lacking a functional gene for the endogenous ligand preproenkephalin ( $p p E N K$ ) show a similar tolerance deficit. In addition, we found that the DOR-1 and ppENK knock-outs as well as the NMDA receptor-deficient $129 S 6$ inbred mouse strain, which also lacks tolerance, exhibit antagonist-induced opioid withdrawal. These data demonstrate that although signaling pathways involving ppENK, DOR, and NMDA receptor are necessary for the ex- pression of morphine tolerance, other pathways independent of these factors can mediate physical dependence. Moreover, these studies illustrate that morphine tolerance can be genetically dissociated from physical dependence, and thus provide a genetic framework to assess more precisely the contribution of various cellular and molecular changes that accompany morphine administration to these processes.

Key words: morphine; opiate; $\mu$-opioid receptor; $\delta$-opioid receptor; preproenkephalin; NMDA receptor; tolerance; dependence
Several lines of evidence indicate that the $\delta$-opioid receptor (DOR) is essential for morphine tolerance. Initial experiments showed that blockade of DOR with antagonists (Abdelhamid et al., 1991) or DOR downregulation using antisense probes (Kest et al., 1996) disrupted the development of tolerance. More recently, analysis of mice with a mutation in the DOR-1 gene confirmed the specificity of these treatments by showing that analgesic tolerance to morphine after daily injection of a fixed morphine dose was abolished in DOR-1 knock-out (KO) mice (Zhu et al., 1999).

Because DOR- 1 was required for morphine tolerance, we believed that an endogenous opioid peptide ligand would also be necessary to activate the DOR in the tolerance pathway. It has been shown previously that simultaneous administration of enkephalins (ENKs), delivered either intracerebroventricularly (Lee et al., 1980) or intrathecally (Rady et al., 2001) with morphine, attenuates morphine analgesia. These anti-analgesic actions, coupled with the fact that the ENKs bind with greatest affinity to DOR (Weber et al., 1983; Corbett et al., 1984), suggest a possible role for these peptides in morphine tolerance. Thus, we investigated the importance of preproenkephalin ( $p p E N K)$ derived peptides in morphine tolerance by assessing the effects of chronic morphine treatment in a novel mouse strain bearing a null mutation of the $p p E N K$ gene.

\footnotetext{
Received June 5, 2002; revised Sept. 30, 2002; accepted Oct. 3, 2002.

This work was supported by National Institutes of Health Grants DA-08622 (J.P.), DA-09040 (J.P.), DA-07242 (G.W.P.), DA-00220 (G.W.P.), and TG MH/AG19957, and by National Institute on Drug Abuse predoctoral fellowship F30-DA-05964 (J.N.). We thank Elizabeth Robertson for CCE ES cells, Chris Evans for the enkephalin antibodies, and Rafael Maldonado for discussion of withdrawal paradigms. We gratefully acknowledge the technical assistance of Min-Sing Hsu.

Correspondence should be addressed to John E. Pintar, Department of Neuroscience and Cell Biology, University of Medicine and Dentistry of New JerseyRobert Wood Johnson Medical School, Center for Advanced Biotechnology and Medicine, Room 326, 675 Hoes Lane, Piscataway, NJ 08854. E-mail: pintar@ cabm.rutgers.edu.

Copyright (C) 2002 Society for Neuroscience $\quad 0270-6474 / 02 / 2210906-08 \$ 15.00 / 0$
}

Considerable controversy exists regarding whether the phenomena of opiate tolerance and physical dependence share a common mechanism. Early work observed a very high correlation between the extent of tolerance and the severity of dependence after morphine treatment in both the whole animal (Way et al., 1969) and in bioassays (Rezvani et al., 1990), suggesting that the two phenomena are closely linked. Moreover, in several studies, blockade of the NMDA receptor/nitric oxide synthase (NOS) cascade was shown to attenuate both tolerance and dependence, again suggesting a link between the two phenomena (Trujillo and Akil, 1991; Kolesnikov et al., 1993; Elliott et al., 1994; Mao et al., 1994; Pasternak and Inturrisi, 1995; Pasternak et al., 1995; Gonzalez et al., 1997).

In contrast, more recent experiments have suggested that distinct biochemical pathways underlie tolerance and dependence. For example, both LY293558 [(3SR, 4aRS, 6RS, 8aRS)-6-[2-(iHtetrazol-5-yl)ethyl]-1,2,3,4,4a,5,6,7,8,8a-decahydroiso-quinoline-3carboxylic acid], an AMPA receptor antagonist, and LY235959 [(-)-6-[phosphonomethyl-1,2,3,4,4a,5,6,7,8,8a-decahydroisoquinoline-2-carboxylate]], a competitive NMDA receptor antagonist, have a greater effect on tolerance than on dependence (McLemore et al., 1997). Furthermore, data suggest that after local peripheral administration of $\mathrm{D}-\mathrm{Ala}^{2}-\mathrm{N}-\mathrm{Me}-\mathrm{Phe}^{4}-\mathrm{Glycol}^{5}$ enkephalin to the rat hindpaw, NOS mediates tolerance and protein kinase C mediates dependence (Aley and Levine, 1997a,b). Together, these findings suggest that the mechanisms underlying tolerance and dependence are at least partially distinct.

Although previous studies have explored the role of $p p E N K$ derived peptides (Lee et al., 1980; Rady et al., 2001), the DOR (Zhu et al., 1999), and the NMDA receptor (Trujillo and Akil, 1991, 1994, 1995; Trujillo, 2000) in analgesic tolerance paradigms, their role in physical dependence has been less thoroughly studied. To determine the role of these factors in physical dependence, we investigated physical dependence, as assessed by 


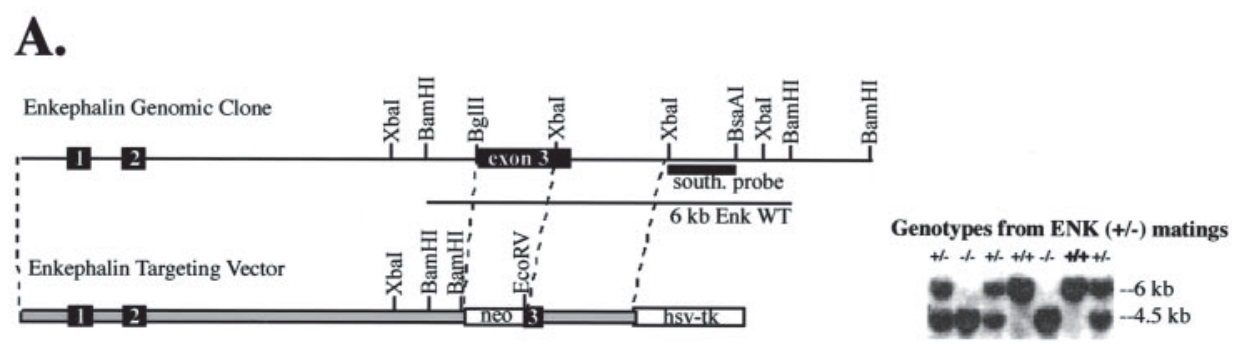

Figure 1. Gene targeting of the $p p E N K$ gene and morphine tolerance in $p p E N K$ KO mice. $A$, A murine $\mathrm{Sw} 129 / \mathrm{ReJ}$ genomic library was prepared from which the $p p E N K$ gene was isolated and characterized. The targeting vector was produced by subcloning two genomic DNA fragments, denoted by dotted lines, into a pBS-SKII-based cassette (obtained from Dr. S. Potter, University of Cincinnati) containing the neo and HSV-tk genes, both driven by the HSV-tk promoter. First, a $2.1 \mathrm{~kb} X b a \mathrm{I}$ fragment, containing the $3^{\prime}$ part of exon 3 downstream of ENK-coding sequences and part of intron 3, was subcloned into a HindIII blunt cassette. The resulting construct was digested with NotI, blunted, and ligated with a 6 kb SalI-BglII fragment containing exon 1 , intron 1 , exon 2 , and part of intron 2 . CCE ES cells were electroporated with this targeting vector, and $\mathrm{KO}$ mice were produced by standard techniques. Southern blot analysis confirmed that all genotypes appear in offspring from mice heterozygous for the mutant ppENK allele. $B$, In situ hybridization was performed using riboprobes complementary to exon 3 ppENK peptideencoding sequences. Although prominent expression was detected in the striatum of wild-type mice, hybridization was absent in homozygous mutant mice. $C$, Immunocytochemistry was performed using rabbit antibodies raised and affinity-purified against mouse ppENK-derived peptides (see Materials and Methods). Although prominent staining was detected in the striatum of wild-type mice, staining was absent in homozygous mutant mice. A representative high-power micrograph of ME(13) antibody staining is shown. Similar results were obtained with the BAM 18 antibody. $D$, Groups of mice $(n=8)$ generated from heterozygous matings received morphine $(5 \mathrm{mg} / \mathrm{kg}$, s.c.) daily for $10 \mathrm{~d}$. Analgesia was assessed using the radiant-heat tailflick test before drug administration on day 1 and $30 \mathrm{~min}$ afterward on the indicated days. Data in the graph are expressed as percentages of mice exhibiting analgesia; significance was assessed using a Fisher's exact test. Data expressed as \%MPE were also analyzed using a one-way ANOVA followed by a Fisher's PLSD test. Both analyses revealed that after $10 \mathrm{~d}$ of morphine treatment, wild-type mice exhibited a significant decrease in analgesia, whereas homozygous mutant mice did not.

antagonist-precipitated withdrawal, in both the $p p E N K$ and DOR-1 KO mice, as well as the NMDA-deficient 129S6 inbred mouse strain.

\section{MATERIALS AND METHODS}

ppENK gene targeting. A murine Sw129/ReJ genomic library was prepared, from which the ENK gene was isolated. The targeting vector was produced by subcloning two genomic DNA fragments into a pBS-SKIIbased cassette (obtained from Dr. S. Potter, University of Cincinnati, Cincinnati, $\mathrm{OH}$ ) containing the neo and herpes simplex virus (HSV)thymidine kinase $(t k)$ genes, both driven by the HSV-tk promoter. First,

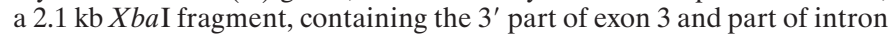
3 , was subcloned into a HindIII blunt cassette. The resulting construct was digested with NotI, blunted, and ligated with a $6 \mathrm{~kb}$ SalI-BglII fragment containing exon 1 , intron 1 , exon 2 , and part of intron 2. CCE embryonic stem (ES) cells were electroporated with the targeting vector, and KO mice were produced by standard techniques.

In situ hybridization. The ${ }^{35} \mathrm{~S}$-labeled $p p E N K$ RNA transcripts were synthesized using Riboprobe Gemini Systems (Promega, Madison, WI) from a plasmid pSP65, which contained a 520 bp PstI fragment of rat $p p E N K$ cDNA corresponding to the C-terminal region of $p p E N K$. The resulting transcripts were purified on a Sephadex G-50 column (Roche Molecular Biochemicals, Indianapolis, IN) and used for in situ hybridization as described previously (Zheng and Pintar, 1995).

Immunocytochemistry. Wild-type and $p p E N K \mathrm{KO}$ mice were perfusion-fixed with $4 \%$ paraformaldehyde. The brains were removed and embedded in OCT for cryostat sectioning. Brain sections $(15 \mu \mathrm{m})$ were collected from wild-type and $p p E N K \mathrm{KO}$ mice at the level of the striatum. Rabbit primary antibodies ME(13) and BAM18 were raised against mouse $p p E N K$-derived peptides using methods described previously (Weber et al., 1982) and were affinity-purified before being used as described previously (Mastrogiacomo et al., 1994). Sections were then incubated overnight at $4^{\circ} \mathrm{C}$ with both primary antibodies using a 1:2000 dilution for $\mathrm{ME}(13)$ and a 1:6000 dilution for BAM 18. The sections were then incubated for $1 \mathrm{hr}$ at room temperature with secondary biotinylated anti-rabbit antibody (Roche Molecular Biochemicals) in $1 \times$ PBS. Peroxidase amplification was performed using a Vectastain $\mathrm{ABC}$ kit (Vector Laboratories, Burlingame, CA). The peroxidase reaction was then initiated with a short incubation with 3,3' diaminobenzidine (Sigma, St. Louis, MO) and terminated with a quick rinse in $1 \times$ PBS. The slides were then dehydrated and coverslipped with Permount (Fisher, Pittsburgh, PA).

Baseline nociception, and morphine potency, efficacy, and tolerance in ppENK KO mice. Wild-type, heterozygous, and homozygous mutant mice were produced from matings of heterozygous mice maintained on a mixed 129S6 and C57BL/6J background. Baseline nociceptive responses were assessed using the radiant-heat tailflick assay, with a low beam intensity producing an average latency of $\sim 10 \mathrm{sec}$ in wild-type mice and a high beam intensity producing an average latency of $2-3 \mathrm{sec}$ in wildtype mice.

To assess tolerance, mice were given injections of morphine once daily at a dose of $5 \mathrm{mg} / \mathrm{kg}$ for a total of $10 \mathrm{~d}$. Nociceptive thresholds were determined using a high beam intensity before morphine injection on day 1 and $30 \mathrm{~min}$ after injection on days 1-10. Analgesia was defined as a doubling of baseline tailflick latency; data were graphed as the percentage of mice exhibiting analgesia. Statistical significance was assessed using Fisher's exact test. In addition, tailflick latencies and maximal possible effect (\%MPE) were compared using an ANOVA followed by a Fisher's PLSD test. No differences in significance were found between methods.

To assess potency, groups of naive mice $(n=8-10)$ were used to determine $\mathrm{ED}_{50}$ values in wild-type and $p p E N K \mathrm{KO}$ mice. Separate groups of mice $(n=8-10)$ were then treated daily with morphine (5 $\mathrm{mg} / \mathrm{kg}$, s.c.) and $\mathrm{ED}_{50}$ values were determined again after $10 \mathrm{~d}$ of 
Table 1. Effect of chronic morphine administration in wild-type and ppENK KO mice

\begin{tabular}{llcc} 
& \multicolumn{2}{c}{ Morphine $\mathrm{ED}_{50}(\mathrm{mg} / \mathrm{kg}$, s.c. $)(95 \%$ confidence limits $)$} \\
\cline { 2 - 4 } & Naive mice & Chronically treated mice & Shift \\
\hline Wild type & $4.2(3.3,5.3)$ & $13.4(11.7,15.3)$ & $3.2^{*}$ \\
ppENK KO & $3.7(2.8,4.8)$ & $4.2(4.3,5.3)$ & 1.1 \\
\hline
\end{tabular}

Groups of naive mice $(n=8-10)$ were used to determine $\mathrm{ED}_{50}$ values in wild-type and $p p E N K \mathrm{KO}$ mice. Separate groups of mice $(n=8-10)$ were then treated daily with morphine $\left(5 \mathrm{mg} / \mathrm{kg}\right.$, s.c.), and $\mathrm{ED}_{50}$ values were determined again after $10 \mathrm{~d}$ of treatment. The shift in wild-type mice was significant, whereas that in the $\mathrm{KO}$ was not. Analysis of $\mathrm{ED}_{50}$ values from naive mice revealed no significant difference in baseline morphine sensitivity between genotypes. *Significance was determined by the lack of overlap of $95 \%$ confidence limits.

treatment. $\mathrm{ED}_{50}$ values were determined using the GraphPad software package (GraphPad Software Inc., San Diego, CA) Prism. Significance was determined by the lack of overlap of $95 \%$ confidence limits. Efficacy was determined by assessing the percentage of mice exhibiting maximal analgesia at a dose of $10 \mathrm{mg} / \mathrm{kg}(n=8-10$ per genotype).

Morphine dependence in DOR-1and ppENK KO mice. A $75 \mathrm{mg}$ morphine slow-release pellet was implanted subcutaneously in the nape of the neck. The nociceptive thresholds of the mice were then tested once a day using the radiant-heat tailflick test. At $72 \mathrm{hr}$ after implantation, withdrawal was induced by a subcutaneous injection of $5 \mathrm{mg} / \mathrm{kg}$ naltrexone. After injection, mice were observed for $30 \mathrm{~min}$, and eight withdrawal signs were recorded. Four signs were counted (jumping, wet-dog shakes, paw tremor, and sniffing), and four signs were quantally graded (teeth chattering, ptosis, diarrhea, and body tremor). For the quantally graded signs, each mouse received a score of 1 for every 5 min interval in which the sign was present, making the lowest possible score 0 and the highest possible score 6 . The data from each of these signs were given a weighted value and used to compute a global withdrawal score (Maldonado et al., 1992, 1996). Statistical analysis of jumping, wet-dog shakes, paw tremor, and sniffing was performed using a two-way ANOVA. An analysis of global withdrawal score, teeth chattering, ptosis, diarrhea, and tremor was performed using a nonparametric Mann-Whitney $U$ test.

\section{RESULTS}

$p p E N K$ mutant mice contain a deletion of exon 3 sequences that encode all ENK-related peptides at this locus (Fig. 1A). The deletion was verified using in situ hybridization and immunocytochemistry. Both peptide-encoding $p p E N K \mathrm{mRNA}$ and $p p E N K$ encoded immunoreactivity, as assessed with two antibodies raised against $p p E N K$-derived peptides, were absent in the striatum of homozygous mutant mice (Fig. $1 B, C$ ). Analysis of tailflick latencies in untreated offspring of mice heterozygous for the null ENK allele at both low beam intensities $(+/+, 10.7 \pm 0.3 ;-/-, 11.0 \pm$ $0.2 ; p>0.05)$ and at high beam intensities used to assess analgesia $(+/+, 3.1 \pm 0.1 \mathrm{sec} ;-/-3.1 \pm 0.1 \mathrm{sec} ; p>0.05)$ showed no significant differences in baseline nociceptive thresholds between wild-type and $p p E N K$ homozygous mutant mice.

Naive mice were then evaluated for morphine potency and efficacy. A cumulative dose paradigm was used to show that morphine sensitivity was similar between wild-type and homozygous mutant mice (Table 1), indicating that naive wild-type and mutant mice experience a similar stimulus after morphine administration. Similar morphine analgesic potencies were also seen in wild-type and DOR-1 KO null mice (Zhu et al., 1999). At a dose of $10 \mathrm{mg} / \mathrm{kg}$, morphine produced maximal analgesia in $60 \%$ of both wild-type and ppENK homozygous mutant mice and revealed no difference in efficacy between genotypes. Analysis of DOR-1 KO mice showed that morphine at a dose of $10 \mathrm{mg} / \mathrm{kg}$ produced maximal analgesia in $56 \%$ of wild-type mice and $67 \%$ of DOR-1 KO mice ( $p>0.05$; Fisher's exact test), revealing no change in morphine efficacy in that mutant strain as well.

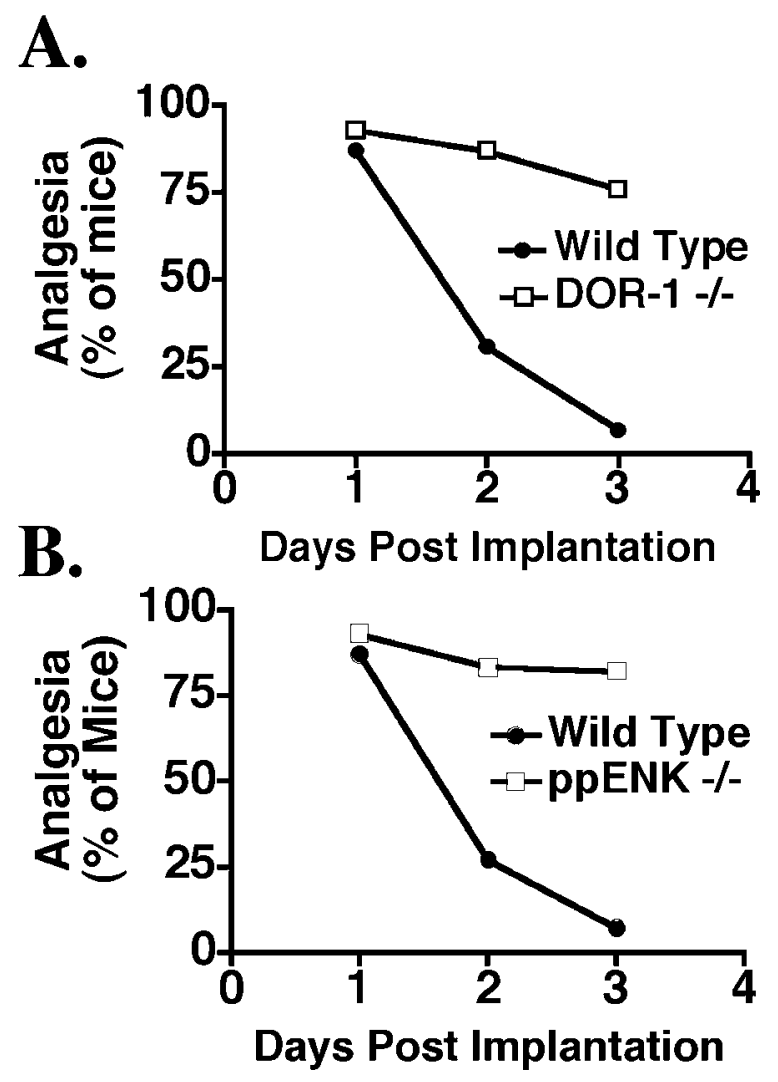

Figure 2. Morphine tolerance in DOR-1 KO and ppENK KO mice after pellet implantation. Groups of DOR-1 $(A ; n=21-28)$ and $\operatorname{ppENK}(B ; n=$ 15-20) mice generated from mating heterozygous mice of each strain were implanted with a single $75 \mathrm{mg}$ morphine pellet. Analgesia was assessed daily for $3 \mathrm{~d}$ after implantation. The data in the graph are expressed as the percentage of mice exhibiting analgesia; significance was assessed using a Fisher's exact test. Data expressed as \%MPE were also analyzed using a one-way ANOVA followed by a Fisher's PLSD test. Both analyses revealed that after $3 \mathrm{~d}$ of morphine treatment, wild-type mice exhibited a significant decrease in analgesia, whereas DOR-1 and ppENK homozygous mutant mice did not.

Offspring of mice heterozygous for the null $p p E N K$ allele were then evaluated for morphine tolerance. In a daily injectiontolerance paradigm, wild-type mice that received a fixed morphine dose $(5 \mathrm{mg} / \mathrm{kg})$ and were tested daily showed, as expected, a significant decrease in morphine analgesia during the $10 \mathrm{~d}$ of treatment, whereas $p p E N K$ homozygous mutant mice showed no change in analgesia over the same time course; heterozygotes showed an intermediate response (Fig. 1D). Moreover, after $10 \mathrm{~d}$ of chronic morphine treatment, the morphine $\mathrm{ED}_{50}$ value in wild-type mice was shifted 3.2-fold to the right, whereas morphine potency in $p p E N K \mathrm{KO}$ mice was unchanged (Table 1).

As described in the introductory remarks, considerable controversy exists as to whether the phenomena of opiate tolerance and physical dependence share a common mechanism. To determine whether morphine tolerance and physical dependence can be separated genetically, we assessed physical dependence in both the DOR-1 and ppENK KO strains using an antagonist-induced withdrawal paradigm after pellet implantation (Maldonado et al., 1992, 1996). Measurements of nociceptive thresholds throughout the $3 \mathrm{~d}$ of pellet implantation (Fig. 2) revealed statistically insignificant changes in analgesia, thus demonstrating a marked reduction in tolerance in both DOR-1 and ppENK mutant mice at the time when physical dependence was assessed. 


\section{Global Withdrawal} Score
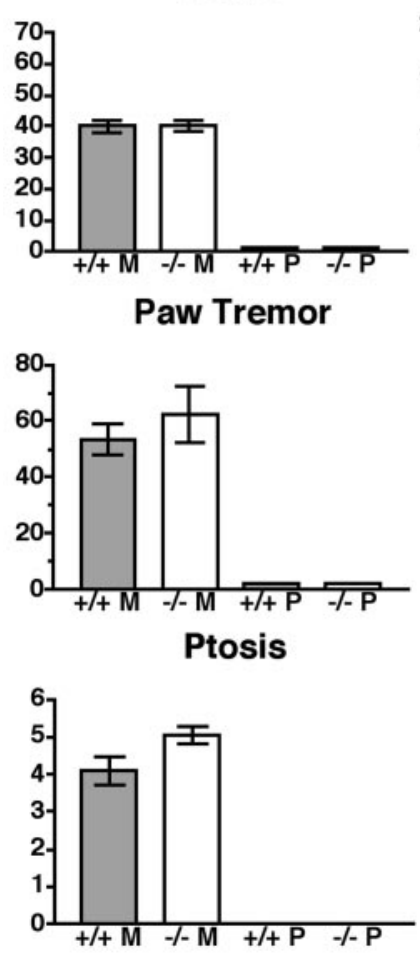

Jumps
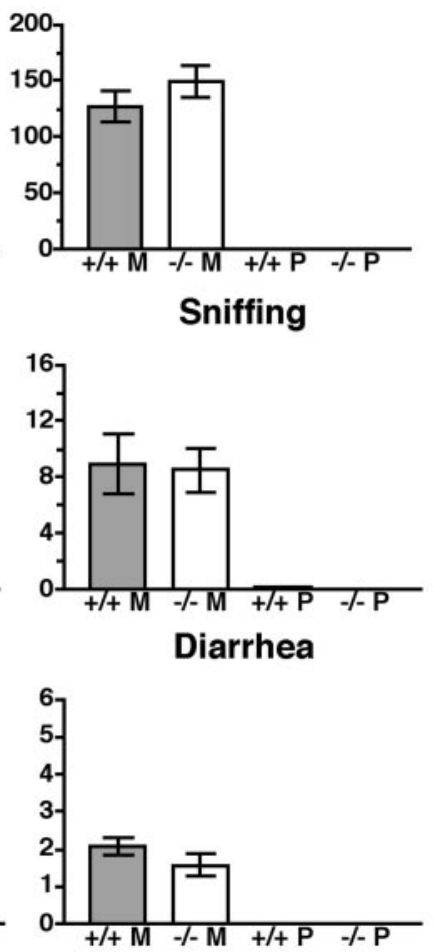

Wet-Dog Shakes
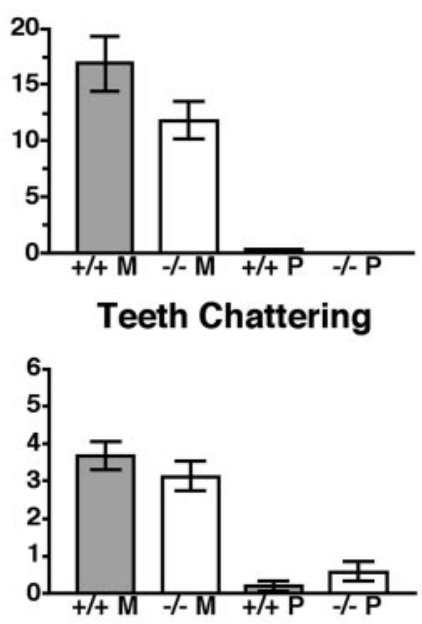

Tremor

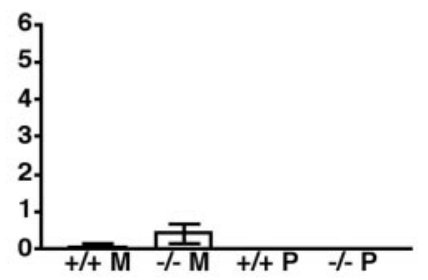

Figure 3. Morphine withdrawal in DOR-1 KO mice. Groups of mice, generated from heterozygous matings, as shown in Figure $2 A(n=21-28)$, were implanted with a single $75 \mathrm{mg}$ morphine pellet. At $72 \mathrm{hr}$ after implantation, each mouse received a dose of $5 \mathrm{mg} / \mathrm{kg}$ naltrexone, and withdrawal signs were recorded for $30 \mathrm{~min}$. Four signs (jumping, wet-dog shakes, paw tremor, and sniffing) were counted. Four signs (teeth chattering, ptosis, diarrhea, and tremor) were quantally graded. For these signs, a score of 1 was received for each 5 min interval during which the sign was present, making the maximum possible score 6. A weighted score was then given to each of these signs, and a global withdrawal score was calculated for each animal. Significance was assessed using an ANOVA for jumping, wet-dog shakes, sniffing, and paw tremor or a Mann-Whitney $U$ test for global withdrawal score, teeth chattering, ptosis, diarrhea, and tremor. No significant difference was found between wild-type and DOR-1 KO mice with regard to the global withdrawal score or any of the individual signs of withdrawal. Marked differences between the wildtype strains from the DOR KO and the ppENK KO strains (Fig. 5) were noted in several withdrawal signs. These changes were likely attributable to varying levels of genetic determinants from either of the two parent strains present in our outbred KO strains. To eliminate this confounding element, homozygous mutant mice were compared only with the wild-type mice generated in the same round of heterozygous matings. $M$, Morphine; $P$, placebo. $p<0.05$.

Analysis of eight withdrawal signs in DOR-1 homozygous mutant mice revealed no significant differences between the mutants and littermate wild-type controls in the global withdrawal score (Fig. 3). Moreover, analysis of the individual signs of withdrawal revealed significant changes only in ptosis, and even then the difference was slight (Fig. 3). Thus, the expression of morphine tolerance can be separated genetically from physical dependence in DOR-1 KO mice under the same chronic treatment paradigm.

Analysis of withdrawal in the $p p E N K \mathrm{KO}$ mice revealed that these mice, like the DOR-1 KO mice, also develop a level of physical dependence that is at least comparable with that of wild-type mice of the same background. Most importantly, the presence of withdrawal (Fig. 4) in the absence of morphine tolerance (Fig. $2 B$ ) in this second $\mathrm{KO}$ strain provides additional evidence that the pathways mediating morphine tolerance and dependence can be dissociated genetically using the same chronic treatment paradigm. Interestingly, $p p E N K \mathrm{KO}$ mice show an increase in a subset of withdrawal signs, namely wet-dog shakes and sniffing, which contribute to an elevated global withdrawal score (Fig. 4).

Physical dependence was also assessed in the morphinetolerance-deficient 129S6 inbred mouse strain. As with the DOR-1 and ppENK KO mice, a $75 \mathrm{mg}$ morphine pellet was implanted subcutaneously, and the mice were then tested for analgesia once daily for $3 \mathrm{~d}$ after implantation. Consistent with previous findings (Kolesnikov et al., 1998), no tolerance was seen throughout the $3 \mathrm{~d}$ of the experiment (Fig. 5). However, on day 3, when tolerance is clearly absent, mice implanted with morphine pellets showed a significantly greater global withdrawal score and expressed five of the individual withdrawal signs to a significantly greater extent than mice implanted with placebo pellets (Fig. 6).
Although it is difficult to compare global withdrawal scores across experiments because of the different genetic backgrounds of the 129S6 mice and the mixed-background DOR-1 and ppENK KO mice, the expression of withdrawal in the 129S6 mice identifies a third strain in which tolerance and dependence can be dissociated.

\section{DISCUSSION}

Our previous findings in KO mice have shown that DOR is required for morphine tolerance (Zhu et al., 1999), results consistent with antisense studies targeting DOR-1 (Kest et al., 1996). However, because morphine could possibly function as a DOR agonist, it was uncertain whether morphine or endogenous opioids produce the necessary activation of DOR during chronic opiate treatment. Because morphine tolerance is absent in the ppENK KO mice, which have a functional DOR, the ability of morphine to activate DOR is not sufficient to produce tolerance. Thus, the present findings demonstrate that release and activity of $p p E N K$-derived peptides during chronic morphine exposure is a crucial step in the expression of tolerance in the daily injection paradigm. Moreover, the similar deficit in morphine tolerance seen in both the DOR-1 and ppENK KO strains indicates that $p p E N K$ and $D O R-1$ are required for one or more steps in a morphine tolerance pathway that is activated during the daily injection paradigm and possibly act as a ligand-receptor pair at a specific location in this pathway.

Previous characterization of the DOR-1 KO mice has revealed a novel, upregulated " $\delta$-like" receptor system in the homozygous mutant mice (Zhu et al., 1999). This receptor could conceivably interfere with the molecular adaptations that accompany chronic morphine exposure and possibly interfere with tolerance in the mutant mice. However, a role for this novel receptor in the 
Global Withdrawal Score

Figure 4. Morphine withdrawal in $p p E N K \mathrm{KO}$ mice. Groups of mice, generated from heterozygous matings, as shown in Figure $2 B(n=15-20)$, were implanted with a single $75 \mathrm{mg}$ morphine pellet. At $72 \mathrm{hr}$ after implantation, each mouse received a dose of $5 \mathrm{mg} / \mathrm{kg}$ naltrexone, and withdrawal signs were recorded for $30 \mathrm{~min}$. Four signs (jumping, wet-dog shakes, paw tremor, and sniffing) were counted. Four signs (teeth chattering, ptosis, diarrhea, and tremor) were quantally graded. For these signs, a score of 1 was assigned for each 5 min interval during which the sign was present, making the maximum possible score 6 . A weighted score was given to each of these signs, and a global withdrawal score was calculated for each animal. Significance was assessed using an ANOVA for jumping, wet-dog shakes, sniffing, and paw tremor or a Mann-Whitney $U$ test for global withdrawal score, teeth chattering, ptosis, diarrhea, and tremor. Analysis revealed a significant increase in global withdrawal score, wet-dog shakes, and sniffing in $p p E N K \mathrm{KO}$ mice compared with controls. $M$, Morphine; $P$, placebo. $* p<0.05$.

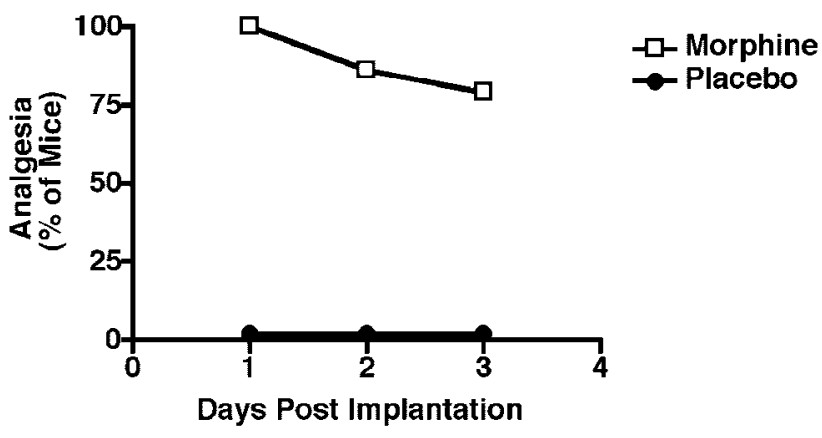

Figure 5. Morphine tolerance in 129S6 mice after pellet implantation. Groups of mice (placebo, $n=5$; morphine, $n=15$ ) were implanted with a single $75 \mathrm{mg}$ morphine pellet. Analgesia was assessed daily for $3 \mathrm{~d}$ after implantation. Significance was assessed using a one-way ANOVA. Data in the graph are expressed as a percentage of mice exhibiting analgesia, and significance was assessed using a Fisher's exact test. Data expressed as $\%$ MPE were also analyzed using a one-way ANOVA followed by a Fisher's PLSD test. Neither analysis showed a significant decrease in analgesia throughout the $3 \mathrm{~d}$ of testing.

tolerance deficit is discounted by the fact that the novel system is not upregulated in the $p p E N K \mathrm{KO}$ mice, as demonstrated by a lack of BW373U86 analgesia in these mice (data not shown). This finding indicates that the tolerance deficiency in the DOR-1 and $p p E N K \mathrm{KO}$ mice likely develops independently of the upregulation of the novel system.

Several studies have suggested that $\mu$-opioid receptor (MOR)-1 itself is not internalized by morphine either in vitro (Arden et al., 1995; Keith et al., 1996) or in vivo (Sternini et al., 1996; Keith et al., 1998). However, in cell lines, morphine will internalize MOR$1 \mathrm{C}$, a variant of MOR that has been implicated in morphine analgesia (Abbadie and Pasternak, 2001), and in vivo chronic
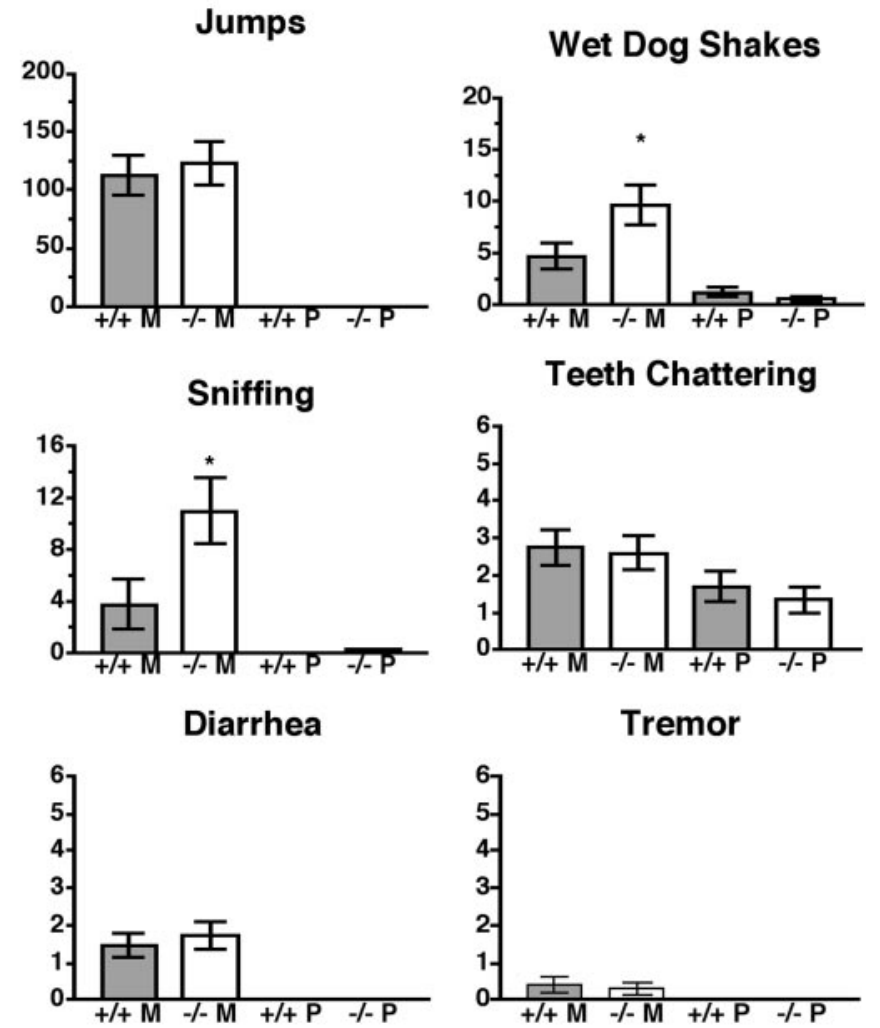

morphine downregulates MOR levels, as assessed by Western blotting (Bernstein and Welch, 1998). In addition, morphine activation of a chimeric MOR bearing the C-terminal domain of DOR is able to produce internalization of wild-type MOR, with which it can interact (He et al., 2002). Because MOR and DOR have been shown to interact in cell lines (Gomes et al., 2000), it is tempting to speculate that the regulation of MOR trafficking by DOR may be involved in the tolerance response. In cells that coexpress both MOR and DOR, DOR activated by release of endogenous ENK could "drag" and internalize MOR complexed with it in response to morphine treatment. The fate of these internalized receptors remains unclear. The classic model of the process views these receptors as targeted for degradation and thereby contributing to receptor downregulation and tolerance, although a recent study has proposed that internalization in fact directly opposes the development of tolerance by promoting receptor resensitization (He et al., 2002). If the DOR were regulating the trafficking of the MOR, the data from our KO mice would suggest that this trafficking facilitates tolerance. Mutation of the DOR-1 or $p p E N K$ gene effectively prevents activation of the DOR portion of the complex, preventing its influence on MOR internalization. Because removal of this influence has resulted in mice without tolerance, it suggests that one way in which the DOR may promote development of tolerance in wild-type mice is by contributing to receptor degradation.

As mentioned above, previous investigation of the DOR-1 KOs established the role of the DOR in morphine tolerance genetically. However, the continued development of dependence in the DOR-1 KOs, which have no detectable $\delta_{1}$ or $\delta_{2}$ binding (Zhu et al., 1999; Filliol et al., 2000), argues against the previously proposed role for $\delta_{2}$ in dependence (Abdelhamid et al., 1991; Miyamoto et al., 1993). Although both the previous experiments and 


\section{Global Withdrawal Score}

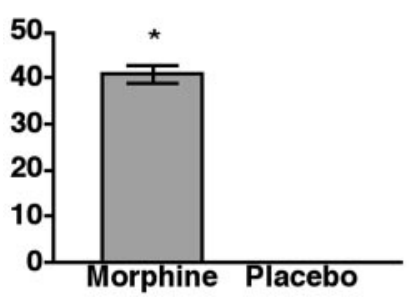

Paw Tremor

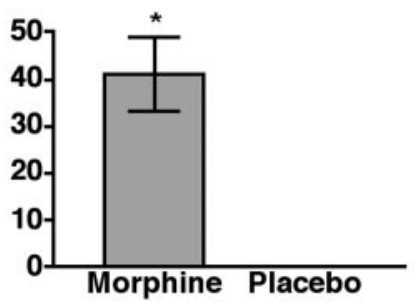

Ptosis

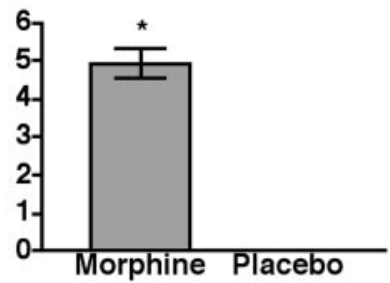

Jumps

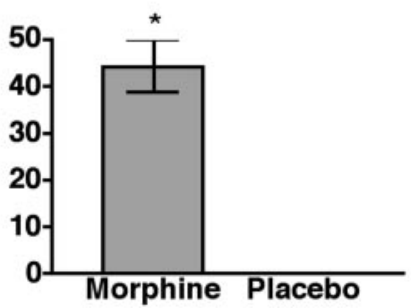

Sniffing
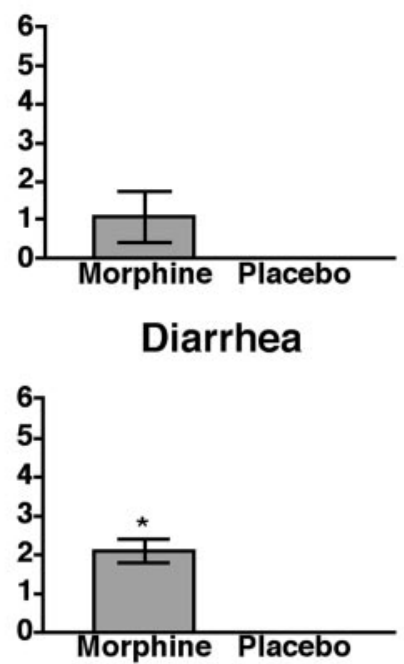

\section{Wet-Dog Shakes}

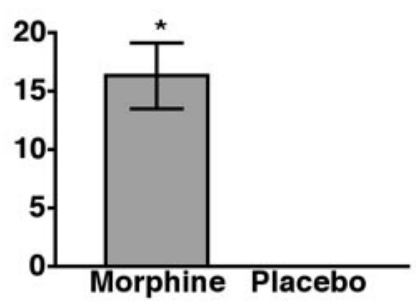

Teeth Chattering
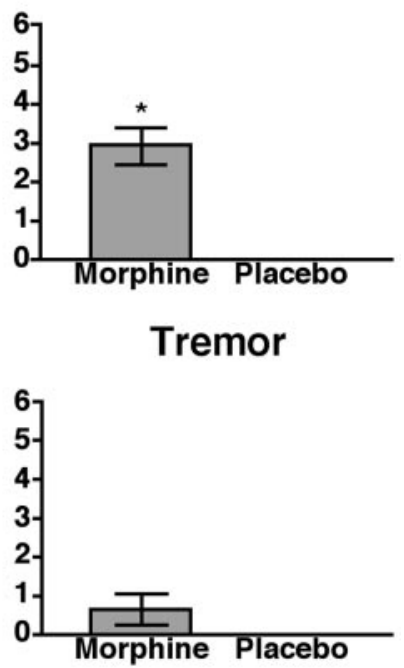

Figure 6. Morphine withdrawal in 129S6 inbred mice. Groups of mice (placebo, $n=5$; morphine, $n=15$ ) were implanted with a single $75 \mathrm{mg}$ morphine pellet. At $72 \mathrm{hr}$ after implantation, each mouse received a dose of $5 \mathrm{mg} / \mathrm{kg}$ naltrexone, and withdrawal signs were recorded for $30 \mathrm{~min}$. Four signs (jumping, wet-dog shakes, paw tremor, and sniffing) were counted. Four signs (teeth chattering, ptosis, diarrhea, and tremor) were quantally graded. For these signs, a score of 1 was assigned for each 5 min interval during which the sign was present, making the maximum possible score 6 . A weighted score was given to each of these signs, and a global withdrawal score was calculated for each animal. Significance was assessed using an ANOVA for jumping, wet-dog shakes, sniffing, and paw tremor or a MannWhitney $U$ test for global withdrawal score, teeth chattering, ptosis, diarrhea, and tremor. Compared with mice implanted with placebo pellets, mice implanted with morphine pellets showed a significant increase in global withdrawal score, jumps, wet-dog shakes, paw tremor, teeth chattering, ptosis, and diarrhea. ${ }^{*} p<0.05$. the current study used $3 \mathrm{~d}$ of pellet implantation to induce dependence, the discrepancy may possibly be explained by the high doses and long-term course of the treatments with naltrindole (NTI) and 5'-naltrindoleisothiocyanate used in the previous studies or by the additional nonopioid actions of NTI, which have been described recently in lymphocytes of triple opioid receptor KO mice (Gaveriaux-Ruff et al., 2001). Together, these findings demonstrate that the DOR plays no required role in physical dependence and suggest that these DOR antagonists may not be as selective as previously thought and may interact with alternative receptors.

Although a large body of evidence previously implicated the NMDA receptor in morphine tolerance, the role for this receptor in physical dependence has remained controversial. Although most investigators have found similar effects of NMDA receptor antagonism on both tolerance and dependence (Trujillo and Akil, 1991; Mao et al., 1994; Manning et al., 1996; Gonzalez et al., 1997; Mao, 1999), some studies have revealed that tolerance is much more sensitive to NMDA receptor antagonists than physical dependence (Thorat et al., 1994; McLemore et al., 1997). Moreover, the locomotor hyperactivity that often accompanies the administration of NMDA receptor antagonists (Trujillo, 2000) also suggests that these drugs might not be specifically interfering with dependence. Data from two separate groups strongly indicate that 129S6 mice possess an NMDA receptor defect (Kolesnikov et al., 1998; Rady et al., 2001). Although the molecular nature of this abnormality has yet to be identified, our results also support the role of the NMDA receptor in tolerance, because the defect in these mice clearly prevents tolerance from being expressed. However, because the defect has not prevented mor- phine dependence from developing and being expressed after naltrexone challenge, our results indicate that the NMDA receptor plays no required role in this phenomenon.

In summary, the studies reported here have extended our understanding of several aspects of morphine tolerance and dependence. We have first identified $p p E N K$ as a requirement for morphine tolerance, which likely exerts its effects through DOR. Perhaps most importantly, we have also shown that although signaling pathways involving ppENK, the DOR, and the NMDA receptor are necessary for the expression of morphine tolerance, other pathways independent of these factors can mediate physical dependence. This hypothesis is supported not only by the current findings but also by other recent studies. These studies have implicated both the CB1 receptor (Ledent et al., 1999) and $\alpha$-calcitonin gene-related peptide (Salmon et al., 2001) in the pathways that mediate dependence, because strains of mice bearing null mutations of these genes show attenuated morphine dependence but unchanged morphine tolerance. In addition to ppENK, the DOR, and the NMDA receptor investigated in the present study, the $\beta$-arrestin 2 gene has also been implicated in tolerance but not dependence (Bohn et al., 2000). However, these mice show a drastically potentiated and prolonged analgesic response to morphine (Bohn et al., 1999). Thus, the separation of morphine tolerance from physical dependence in the DOR-1 and ppENK KOs, which show no change in baseline morphine sensitivity, provides the first clear evidence describing the role of several factors involved in tolerance under conditions in which morphine efficacy is unchanged.

The finding that the expression of morphine tolerance and physical dependence can be separated genetically carries impor- 
tant implications. Because these two phenomena can no longer be viewed as invariably linked responses accompanying chronic morphine administration, it may be useful to re-evaluate existing drugs, in combination with $D O R-1 / \mathrm{ENK}$ antagonists, to identify differing liabilities for tolerance and for dependence that could significantly alter treatment for chronic pain. Moreover, now that genetic models separating tolerance and withdrawal have been identified, the importance of other molecular changes suspected of playing a role in these processes, such as receptor desensitization, alterations in cAMP signaling, or changes in gene expression (Nestler et al., 1994; Nestler, 1997; Nestler and Aghajanian, 1997; Harrison et al., 1998), can be directly evaluated. Finally, and perhaps most importantly, by identifying the molecular changes that occur in wild-type mice but not in DOR-1 and $p p E N K$ null mice after chronic morphine treatment, additional targets may be identified that can be used to ameliorate the development of morphine tolerance and/or minimize withdrawal. For example, chronic opiate administration results in the uncoupling of the MOR from G-proteins in specific brain regions (Sim et al., 1996; Sim-Selley et al., 2000). However, because the subjects in these experiments experienced both tolerance and dependence during the course of the treatment, it has been difficult to assess which regions are involved in one or both of these phenomena. With strains of mice that lack analgesic tolerance but retain dependence, it should be possible to ascertain the contribution of specific brain regions to either one or both of these consequences of chronic opiate exposure.

\section{REFERENCES}

Abbadie C, Pasternak GW (2001) Differential in vivo internalization of MOR-1 and MOR-1C by morphine. NeuroReport 12:3069-3072.

Abdelhamid EE, Sultana M, Portoghese PS, Takemori AE (1991) Selective blockage of $\delta$ opioid receptors prevents the development of morphine tolerance and dependence in mice. J Pharmacol Exp Ther 258:299-303.

Aley KO, Levine JD (1997a) Dissociation of tolerance and dependence for opioid peripheral antinociception in rats. J Neurosci 17:3907-3912.

Aley KO, Levine JD (1997b) Different mechanisms mediate development and expression of tolerance and dependence for peripheral $\mu$-opioid antinociception in rat. J Neurosci 17:8018-8023.

Arden JR, Segredo V, Wang Z, Lameh J, Sadee W (1995) Phosphorylation and agonist-specific intracellular trafficking of an epitope-tagged $\mu$-opioid receptor expressed in HEK 293 cells. J Neurochem 65:1636-1645.

Bernstein MA, Welch SP (1998) $\mu$-Opioid receptor down-regulation and cAMP-dependent protein kinase phosphorylation in a mouse model of chronic morphine tolerance. Brain Res Mol Brain Res 55:237-242.

Bohn LM, Lefkowitz RJ, Gainetdinov RR, Peppel K, Caron MG, Lin FT (1999) Enhanced morphine analgesia in mice lacking $\beta$-arrestin 2. Science 286:2495-2498.

Bohn LM, Gainetdinov RR, Lin FT, Lefkowitz RJ, Caron MG (2000) $\mu$-Opioid receptor desensitization by $\beta$-arrestin- 2 determines morphine tolerance but not dependence. Nature 408:720-723.

Corbett AD, Gillan MG, Kosterlitz HW, McKnight AT, Paterson SJ, Robson LE (1984) Selectivities of opioid peptide analogues as agonists and antagonists at the $\delta$-receptor. Br J Pharmacol 83:271-279.

Elliott K, Minami N, Kolesnikov YA, Pasternak GW, Inturrisi CE (1994) The NMDA receptor antagonists, LY274614 and MK-801, and the nitric oxide synthase inhibitor, $N G$-nitro-L-arginine, attenuate analgesic tolerance to the $\mu$-opioid morphine but not to $\kappa$ opioids. Pain 56:69-75.

Filliol D, Ghozland S, Chluba J, Martin M, Matthes HW, Simonin F, Befort K, Gaveriaux-Ruff C, Dierich A, LeMeur M, Valverde O, Maldonado R, Kieffer BL (2000) Mice deficient for $\delta$ - and $\mu$-opioid receptors exhibit opposing alterations of emotional responses. Nat Genet 25:195-200.

Gaveriaux-Ruff C, Filliol D, Simonin F, Matthes HW, Kieffer BL (2001) Immunosuppression by $\delta$-opioid antagonist naltrindole: $\delta$ - and triple $\mu^{\prime} 2 \mathrm{f} \delta$ ' $2 \mathrm{f} \kappa$-opioid receptor knockout mice reveal a nonopioid activity. J Pharmacol Exp Ther 298:1193-1198.

Gomes I, Jordan BA, Gupta A, Trapaidze N, Nagy V, Devi LA (2000) Heterodimerization of $\mu$ and $\delta$ opioid receptors: a role in opiate synergy. J Neurosci 20:RC110(1-5).

Gonzalez P, Cabello P, Germany A, Norris B, Contreras E (1997)
Decrease of tolerance to, and physical dependence on morphine by, glutamate receptor antagonists. Eur J Pharmacol 332:257-262.

Harrison LM, Kastin AJ, Zadina JE (1998) Opiate tolerance and dependence: receptors, G-proteins, and antiopiates. Peptides 19:1603-1630.

He L, Fong J, von Zastrow M, Whistler JL (2002) Regulation of opioid receptor trafficking and morphine tolerance by receptor oligomerization. Cell 108:271-282.

Keith DE, Murray SR, Zaki PA, Chu PC, Lissin DV, Kang L, Evans CJ, von Zastrow M (1996) Morphine activates opioid receptors without causing their rapid internalization. J Biol Chem 271:19021-19024.

Keith DE, Anton B, Murray SR, Zaki PA, Chu PC, Lissin DV, Monteillet-Agius G, Stewart PL, Evans CJ, von Zastrow M (1998) $\mu$-Opioid receptor internalization: opiate drugs have differential effects on a conserved endocytic mechanism in vitro and in the mammalian brain. Mol Pharmacol 53:377-384.

Kest B, Lee CE, McLemore GL, Inturrisi CE (1996) An antisense oligodeoxynucleotide to the $\delta$ opioid receptor (DOR-1) inhibits morphine tolerance and acute dependence in mice. Brain Res Bull 39:185-188.

Kolesnikov YA, Pick CG, Ciszewska G, Pasternak GW (1993) Blockade of tolerance to morphine but not to $\kappa$ opioids by a nitric oxide synthase inhibitor. Proc Natl Acad Sci USA 90:5162-5166.

Kolesnikov YA, Jain S, Wilson R, Pasternak GW (1998) Lack of morphine and enkephalin tolerance in 129/SvEv mice: evidence for a NMDA receptor defect. J Pharmacol Exp Ther 284:455-459.

Ledent C, Valverde O, Cossu G, Petitet F, Aubert JF, Beslot F, Bohme GA, Imperato A, Pedrazzini T, Roques BP, Vassart G, Fratta W, Parmentier M (1999) Unresponsiveness to cannabinoids and reduced addictive effects of opiates in CB1 receptor knockout mice. Science 283:401-404.

Lee NM, Leybin L, Chang JK, Loh HH (1980) Opiate and peptide interaction: effect of enkephalins on morphine analgesia. Eur J Pharmacol 68:181-185.

Maldonado R, Negus S, Koob GF (1992) Precipitation of morphine withdrawal syndrome in rats by administration of $\mu-, 100$ - and $\kappa$-selective opioid antagonists. Neuropharmacology 31:1231-1241.

Maldonado R, Blendy JA, Tzavara E, Gass P, Roques BP, Hanoune J, Schutz G (1996) Reduction of morphine abstinence in mice with a mutation in the gene encoding CREB. Science 273:657-659.

Manning BH, Mao J, Frenk H, Price DD, Mayer DJ (1996) Continuous co-administration of dextromethorphan or MK-801 with morphine: attenuation of morphine dependence and naloxone-reversible attenuation of morphine tolerance. Pain 67:79-88.

Mao J (1999) NMDA and opioid receptors: their interactions in antinociception, tolerance and neuroplasticity. Brain Res Brain Res Rev 30:289-304

Mao J, Price DD, Mayer DJ (1994) Thermal hyperalgesia in association with the development of morphine tolerance in rats: roles of excitatory amino acid receptors and protein kinase C. J Neurosci 14:2301-2312.

Mastrogiacomo A, Evans CJ, Gundersen CB (1994) Antipeptide antibodies against a Torpedo cysteine-string protein. J Neurochem 62:873-880.

McLemore GL, Kest B, Inturrisi CE (1997) The effects of LY293558, an AMPA receptor antagonist, on acute and chronic morphine dependence. Brain Res 778:120-126.

Miyamoto Y, Portoghese PS, Takemori AE (1993) Involvement of $\delta 2$ opioid receptors in the development of morphine dependence in mice. J Pharmacol Exp Ther 264:1141-1145.

Nestler EJ (1997) Molecular mechanisms of opiate and cocaine addiction. Curr Opin Neurobiol 7:713-719.

Nestler EJ, Aghajanian GK (1997) Molecular and cellular basis of addiction. Science 278:58-63.

Nestler EJ, Alreja M, Aghajanian GK (1994) Molecular and cellular mechanisms of opiate action: studies in the rat locus coeruleus. Brain Res Bull 35:521-528.

Pasternak GW, Inturrisi C (1995) Pharmacological modulation of opioid tolerance. Exp Opin Invest Drugs 4:217-281.

Pasternak GW, Kolesnikov YA, Babey AM (1995) Perspectives on the $N$-methyl-D-aspartate/nitric oxide cascade and opioid tolerance. Neuropsychopharmacology 13:309-313.

Rady JJ, Holmes BB, Tseng LF, Fujimoto JM (2001) Inverse agonist action of Leu-enkephalin at $\delta 2$-opioid receptors mediates spinal antianalgesia. J Pharmacol Exp Ther 297:582-589.

Rezvani A, Hwang F, Song ZH, Lin ET, Way EL (1990) Supersensitivity to electrical stimulation for assessing physical dependence on opioids in isolated tissues. J Pharmacol Exp Ther 254:52-57.

Salmon AM, Damaj MI, Marubio LM, Epping-Jordan MP, Merlo-Pich E, Changeux JP (2001) Altered neuroadaptation in opiate dependence and neurogenic inflammatory nociception in $\alpha$ CGRP-deficient mice. Nat Neurosci 4:357-358.

Sim LJ, Selley DE, Dworkin SI, Childers SR (1996) Effects of chronic morphine administration on $\mu$ opioid receptor-stimulated $\left[{ }^{35} \mathrm{~S}\right] \mathrm{GTP} \gamma \mathrm{S}$ autoradiography in rat brain. J Neurosci 16:2684-2692.

Sim-Selley LJ, Selley DE, Vogt LJ, Childers SR, Martin TJ (2000) Chronic heroin self-administration desensitizes $\mu$ opioid receptor- 
activated G-proteins in specific regions of rat brain. J Neurosci 20:4555-4562.

Sternini C, Spann M, Anton B, Keith Jr DE, Bunnett NW, von Zastrow M, Evans C, Brecha NC (1996) Agonist-selective endocytosis of $\mu$ opioid receptor by neurons in vivo. Proc Natl Acad Sci USA 93:9241-9246.

Thorat SN, Barjavel MJ, Matwyshyn GA, Bhargava HN (1994) Comparative effects of $N G$-monomethyl-L-arginine and MK-801 on the abstinence syndrome in morphine-dependent mice. Brain Res 642:153-159.

Trujillo KA (2000) Are NMDA receptors involved in opiate-induced neural and behavioral plasticity? A review of preclinical studies. Psychopharmacology (Berl) 151:121-141.

Trujillo KA, Akil H (1991) Inhibition of morphine tolerance and dependence by the NMDA receptor antagonist MK-801. Science 251:85-87.

Trujillo KA, Akil H (1994) Inhibition of opiate tolerance by noncompetitive $N$-methyl-D-aspartate receptor antagonists. Brain Res 633:178-188

Trujillo KA, Akil H (1995) Excitatory amino acids and drugs of abuse: a role for $N$-methyl-D-aspartate receptors in drug tolerance, sensitization, and physical dependence. Drug Alcohol Depend 38:139-154.

Way EL, Loh HH, Shen FH (1969) Simultaneous quantitative assessment of morphine tolerance and physical dependence. J Pharmacol Exp Ther 167:1-8.

Weber E, Evans CJ, Chang JK, Barchas JD (1982) Antibodies specific for $\alpha-N$-acetyl- $\beta$-endorphins: radioimmunoassays and detection of acetylated $\beta$-endorphins in pituitary extracts. J Neurochem 38:436-447.

Weber E, Esch FS, Bohlen P, Paterson S, Corbett AD, McKnight AT, Kosterlitz HW, Barchas JD, Evans CJ (1983) Metorphamide: isolation, structure, and biologic activity of an amidated opioid octapeptide from bovine brain. Proc Natl Acad Sci USA 80:7362-7366.

Zheng M, Pintar JE (1995) Analysis of ontogeny of processing enzyme gene expression and regulation. In: Peptidases and neuropeptide processing, methods in neurosciences (Smith IA, ed), pp 45-64. London: Academic.

Zhu Y, King MA, Schuller AG, Nitsche JF, Reidl M, Elde RP, Unterwald E, Pasternak GW, Pintar JE (1999) Retention of supraspinal $\delta$-like analgesia and loss of morphine tolerance in $\delta$ opioid receptor knockout mice. Neuron 24:243-252. 